\title{
Penerapan Algoritma C4.5 pada Penentuan Tingkat Pemahaman Mahasiswa Terhadap Matakuliah
}

\author{
Nurul Rofiqo', Agus Perdana Windarto ${ }^{2}$, Eka Irawan ${ }^{3}$ \\ STIKOM Tunas Bangsa Pematangsiantar \\ Jl. Jendral Sudirman Blok A No.1/2/3 Pematangsiantar, Medan, Indonesia 21127 \\ nurul.rofiqo@gmail.com
}

\begin{abstract}
This study aims to classify the level of understanding of students at STIKOM Tunas Bangsa Pematangsiantar. STIKOM Tunas Bangsa is one of the private universities in North Sumatra that is engaged in the field of computer science. In carrying out lecture activities, students are required to understand each lecture material provided by the lecturer. There are several things that can affect the level of understanding of students in receiving lecture material. The data source was obtained from the results of the fifth semester and seven student questionnaires in the STIKOM Tunas Bangsa Information System department. Attributes used are as many as five, namely communication, learning atmosphere, learning media, appearance and how to teach. The method used in the research is C4.5 Algorithm and assisted by RapidMiner software to make decision trees. From the results of the study, there were 14 rules for classification in determining the level of understanding with 9 rules, the best status and 5 rules did not understand. C4.5 algorithm can be used in the case of determining the level of understanding of students at STIKOM Tunas Bangsa with an accuracy rate of $87.10 \%$. With this analysis it is expected to be a motivation for students to be able to understand the course well.
\end{abstract}

Keywords: Level of understanding, Method C4.5, Data mining, Decision tree, RapidMiner

\begin{abstract}
Abstrak - Penelitian ini bertujuan melakukan klasifikasi dalam penentuan tingkat pemahaman mahasiswa di STIKOM Tunas Bangsa Pematangsiantar. STIKOM Tunas Bangsa merupakan salah satu perguruan tinggi swasta di Sumatera Utara yang bergerak pada bidang ilmu komputer. Dalam menjalankan kegiatan perkuliahan, mahasiswa dituntut untuk paham terhadap setiap materi perkuliahan yang diberikan oleh dosen. Ada beberapa hal yang dapat mempengaruhi tingkat pemahaman mahasiswa dalam menerima materi perkuliahan. Sumber data didapat dari hasil kuisioner mahasiswa semester lima dan tujuh jurusan Sistem Informasi STIKOM Tunas Bangsa. Atribut yang digunakan sebanyak lima, yaitu komunikasi, suasana pembelajaran, media pembelajaran, penampilan dan cara mengajar. Metode yang digunakan dalam penelitian adalah Algoritma C4.5 dan dibantu dengan software RapidMiner untuk membuat pohon keputusan. Dari hasil penelitian diperoleh 14 rules untuk klasifikasi dalam penentuan tingkat pemahaman dengan 9 rules bestatus paham dan 5 rules berstatus tidak paham. Algoritma C4.5 dapat digunakan dalam kasus penentuan tingkat pemahaman mahasiswa di STIKOM Tunas Bangsa dengan tingkat akurasi $87,10 \%$. Dengan analisis ini diharapkan menjadi motivasi kepada mahasiswa agar dapat memahami mata kuliah dengan baik.
\end{abstract}

Kata kunci : Tingkat pemahaman, Metode C4.5, Data mining, Decision tree, RapidMiner

\section{PENDAHULUAN}

Dalam proses belajar mengajar tingkat pemahaman mahasiswa terhadap matakuliah menjadi hal yang sangat penting. Hal ini berkaitan dengan usaha sebuah perguruan tinggi dalam menghasilkan mahasiswa yang berkualitas. 
Tingkat pemahaman mahasiswa terhadap mata kuliah merupakan salah satu hal utama yang penting bagi berjalannya proses kegiatan perkuliahan. Selain kemauan belajar yang tinggi dari mahasiswa, dosen juga memiliki peran penting dalam menyampaikan materi perkuliahan yang dapat dipahami oleh mahasiswa. Terutama berkaitan dengan bagaimana cara seorang dosen menyampaikan isi materi perkuliahan. Setiap dosen yang memberikan materi memiliki metode pembelajaran yang berbeda kepada mahasiswa mereka. Perbedaan cara mengajar dosen sangat berpengaruh pada hasil yang akan diperoleh oleh mahasiswa ketika proses perkuliahan berlangsung. Adanya mahasiswa yang paham dan tidak paham sangat berpengaruh pada keberhasilan proses pembelajaran. Algoritma yang biasa digunakan dalam data mining yaitu algoritma ID3[1],[2], C4.5[3]-[10],[11]-[18], KMeans [19]-[24], Naive Bayes[23], Support Vector Machines[26], Apriori[27] dan beberapa algoritma data mining lainnya. Algoritma C4.5 dapat digunakan untuk meneliti berbagai macam hal, diantaranya penelitian terkait[28], beliau menyampaikan hasil risetnya mengenai prediksi pada kepuasan mahasiswa terhadap kinerja dosen di Politeknik Tedc Bandung menggunakan algoritma C4.5. Penelitian ini dilakukan untuk mengetahui hal-hal yang berpengaruh terhadap kepuasan mahasiswa yang sebelumnya belum diketahui dengan pasti, serta agar dosen mengetahui lebih awal indikator yang berpengaruh terhadap kepuasan mahasiswa. Dari hasil analisa diperoleh tingkat akurasi sebesar 94,62\%.

Berdasarkan permasalahan diatas, maka penulis mengangkat judul "Penerapan Algoritma C4.5 Pada Penentuan Tingkat Pemahaman Mahasiswa Terhadap Matakuliah". Dari penelitian ini akan dihasilkan sebuah pohon keputusan yang dapat dijadikan sebagai tolak ukur tingkat pemahaman mahasiswa. Diharapkan hasil dari penelitian ini dapat memberikan masukan kepada perguruan tinggi agar dapat memperbaiki sistem pengajaran di perguruan tinggi dalam upaya meningkatkan pemahaman mahasiswa dalam menerima materi dari setiap mata kuliah. Sehingga kemudian akan menghasilkan lulusan STIKOM Tunas Bangsa yang kaya akan ilmu pengetahuan dan berguna bagi masyarakat.

\section{METODOLOGI PENELITIAN ${ }^{i}$}

Penelitian ini dilakukan di STIKOM Tunas Bangsa Pematangsiantar dengan menggunakan algoritma C4.5 dan diproses menggunakan software RapidMiner untuk melakukan klasifikasi pada penentuan tingkat pemahaman mahaiswa terhadap matakuliah. Pengumpulan data dalam penelitian ini dilakukan dengan melakukan wawancara dengan mahasiswa semester ganjil dengan total sampel data yang digunakan adalah 102 mahasiswa pada tahun 2018-2019.

Bentuk diagram alir (flowchart) dapat menggambarkan dengan jelas mengenai proses tahapan maupun langkah dalam klasifikasi menggunakan algoritma C4.5. Dapat dilihat dalam Gambar 1 berupa flowchart sebagai berikut: 


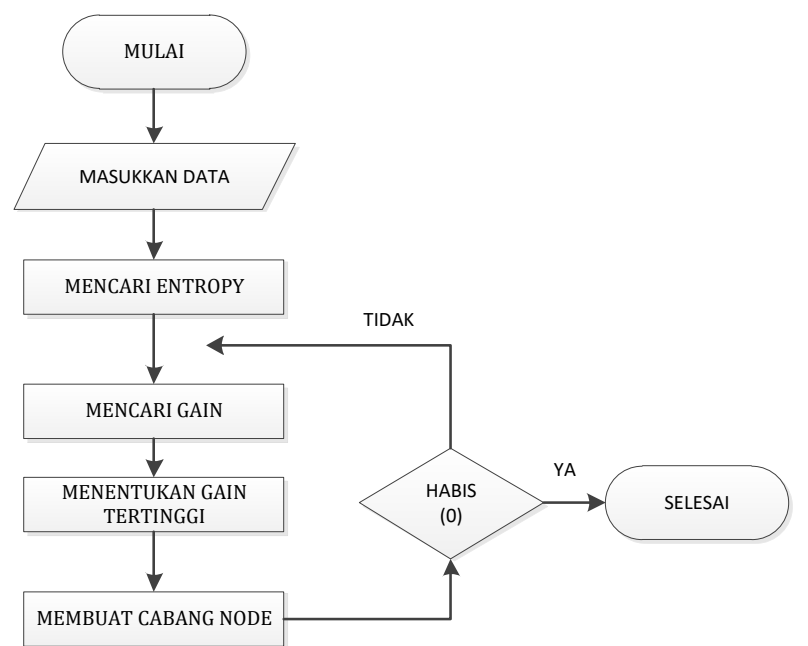

Gambar 1. Flowchart Proses pada Algoritma C4.5

Langkah - langkah melakukan klasifikasi Algoritma Decision Tree C4.5 adalah:

1) Menyiapkan data

2) Memilih atribut sebagai akar

3) Menghitung nilai gain dan entropy

$$
\begin{aligned}
& \text { Gain }(\mathrm{S}, \mathrm{A})=\operatorname{Entrropy}(\mathrm{S})-\sum_{i=1}^{n} \frac{\| \mathrm{SI}]}{\| \Sigma !} * \operatorname{Entropy}(\mathrm{Si}) \\
& \operatorname{Entropy}(A)=\sum_{i=1}^{n}-p i * \log _{2} p i
\end{aligned}
$$

4) Membagi kasus dalam cabang

5) Ulangi proses untuk masing-masing cabang sampai semua kasus pada cabang memiliki kelas yang sama dan atau tidak ada atribut di dalam tupel yang dipartisi lagi dan atau tidak ada tupel di dalam cabang yang kosong.

Metode penelitian ini dilakukan secara sistematik agar mendapatkan alur kerja yang baik, dan dijabarkan menjadi beberapa langkah, yaitu:

a) Studi literatur dilakukan untuk membantu peneliti menelusuri teoriteori yang sedang berkembang mengenai data mining dan Algoritma C4.5 untuk memperoleh metode yang signifikan dengan permasalahan yang ada.

b) Pemilihan objek penelitian dilakukan untuk memudahkan peneliti dalam pengklasifikasian tingkat pemahaman mahasiswa di STIKOM Tunas Bangsa, mengingat terus meningkatnya jumlah mahasiswa tiap tahun agar data tersebut menjadi bermanfaat.

c) Pada penelitian ini digunakan 5 atribut dalam melakukan klasifikasi terhadap tingkat pemahaman mahasiswa. Atribut yang digunakan adalah sebagai berikut:

1) Komunikasi (C1), yang dipertimbangkan sebagai faktor utama antara mahasiswa dan dosen sehingga mempengaruhi mahasiswa memahami mata kuliah.

2) Suasana pembelajaran (C2), dosen yang dapat membangun suasana kelas akan memudahkan mahasiswa memahami setiap materi yang diberikan.

3) Media pembelajaran (C3), Dalam proses pembelajaran media pembelajaran sangat berperan penting. Selain sebagai alat bantu penyampaian materi, media pembelajaran juga dapat mempengaruhi pusat perhatian dari 
mahasiswa. Dosen harus dapat memberikan media pengajaran yang terbaik agar fokus mahasiswa tetap menuju pada materi perkuliahan.

4) Penampilan (C4), Kesiapan dosen dalam mengajar dapat dilihat dari penampilan yang diberikan. Kerapihan melambangkan semangat yang kuat untuk memberikan setiap materi perkuliahan. Dengan penampilan yang baik dapat menarik perhatian mahasiswa untuk lebih fokus menjalani mata kuliah.

5) Cara mengajar (C5), Dalam penyampaian materi ajaran, dosen harus memiliki cara tersendiri agar materi ajarannya mendapat perhatian dari para peserta didik. Tidak monoton dan selalu kreatif adalah yang diharapkan setiap mahasiswa dalam perkuliahan.

d) Menentukan nilai class pada masing-masing atribut. Untuk nilai class pada atribut (C) dapat dilihat dalam tabel dibawah ini :

Tabel 1. Jenis Kelas Data

\begin{tabular}{|l|l|l|}
\hline Atribut & Nama Field & Kelas Data yang Digunakan \\
\hline C1 & Komunikasi & Terbuka, Kadang-kadang, Tertutup \\
\hline C2 & Suasana Pembelajaran & Mendukung, Tidak Mendukung \\
\hline C3 & Media Pembelajaran & Cetak, Non Cetak, Infocus/Proyektor \\
\hline C4 & Penampilan & Menarik, Biasa Saja \\
\hline C5 & Cara Mangajar & Serius dan santai, Serius, Santai, Membosankan. \\
\hline
\end{tabular}

e) Menganalisis data untuk mengklasifikasi tingkat pemahaman mahasiswa di STIKOM Tunas Bangsa sesuai dengan entropi berdasarkan masing-masing atribut menggunakan metode C.45.

\section{HASIL DAN PEMBAHASAN}

Pada bagian ini diberikan hasil penelitian yang dilakukan sekaligus dibahas secara komprehensip. Hasil bisa berupa gambar, Peneliti memperoleh data kuisioner mahasiswa semester ganjil STIKOM Tunas Bangsa tahun ajaran 20182019, yang tercatat dalam format excel yang akan diolah untuk mendapatkan informasi. Adapun tabel data kuisioner mahasiswa, adalah sebagai berikut:

Tabel 2. Data Hasil kuisioner

\begin{tabular}{|l|c|c|c|c|c|c|}
\hline $\begin{array}{l}\text { Respo } \\
\text { nden }\end{array}$ & $\begin{array}{l}\text { Komunik } \\
\text { asi }\end{array}$ & $\begin{array}{c}\text { Suasana } \\
\text { pembelajaran }\end{array}$ & $\begin{array}{c}\text { Media } \\
\text { pembelajaran }\end{array}$ & $\begin{array}{c}\text { Penampi } \\
\text { lan }\end{array}$ & Cara mengajar & Hasil \\
\hline R1 & Terbuka & Mendukung & infocus / proyektor & Menarik & serius dan santai & PAHAM \\
\hline R2 & Terbuka & Mendukung & cetak & Menarik & serius dan santai & PAHAM \\
\hline R3 & $\begin{array}{c}\text { Kadang- } \\
\text { kadang }\end{array}$ & Mendukung & non cetak & biasa saja & serius dan santai & $\begin{array}{c}\text { TIDAK } \\
\text { PAHAM }\end{array}$ \\
\hline R4 & Terbuka & Mendukung & non cetak & biasa saja & Santai & $\begin{array}{c}\text { TIDAK } \\
\text { PAHAM }\end{array}$ \\
\hline R5 & $\begin{array}{c}\text { Kadang - } \\
\text { kadang }\end{array}$ & Mendukung & infocus / proyektor & Menarik & serius dan santai & PAHAM \\
\hline R6 & $\begin{array}{c}\text { Terbuka } \\
\text { Rendukung }\end{array}$ & cetak & biasa saja & serius dan santai & TIDAK \\
\hline R7 & Terbuka & Mendukung & infocus / proyektor & Menarik & serius dan santai & PAHAM \\
\hline R8 & Terbuka & Mendukung & infocus / proyektor & Menarik & serius dan santai & PAHAM \\
\hline R9 & Terbuka & Mendukung & infocus / proyektor & Menarik & serius dan santai & PAHAM \\
\hline R10 & Terbuka & Mendukung & infocus / proyektor & Menarik & serius dan santai & PAHAM \\
\hline
\end{tabular}




\begin{tabular}{|l|c|c|c|c|c|c|}
\hline $\begin{array}{l}\text { Respo } \\
\text { nden }\end{array}$ & $\begin{array}{l}\text { Komunik } \\
\text { asi }\end{array}$ & $\begin{array}{c}\text { Suasana } \\
\text { pembelajaran }\end{array}$ & $\begin{array}{c}\text { Media } \\
\text { pembelajaran }\end{array}$ & $\begin{array}{c}\text { Penampi } \\
\text { lan }\end{array}$ & Cara mengajar & Hasil \\
\hline R11 & Terbuka & Mendukung & infocus / proyektor & Menarik & serius dan santai & PAHAM \\
\hline R12 & Terbuka & $\begin{array}{c}\text { tidak } \\
\text { mendukung }\end{array}$ & non cetak & biasa saja & Serius & $\begin{array}{c}\text { TIDAK } \\
\text { PAHAM }\end{array}$ \\
\hline s/d & $\ldots$ & $\ldots$ & $\ldots$ & $\ldots$ & $\ldots$ & $\ldots$ \\
\hline R102 & $\begin{array}{c}\text { kadang- } \\
\text { kadang }\end{array}$ & Mendukung & non cetak & Menarik & serius dan santai & PAHAM \\
\hline
\end{tabular}

Hasil preprocessing yang didapat kemudian diolah kedalam Decision tree menggunakan software RapidMiner untuk mengetahui klasifikasi tingkat pemahaman mahasiswa yang telah menyelesaikan study, melalui beberapa proses berikut ini:

a) Membuka Aplikasi RapidMiner Studio 8.1.3

Berikut merupakan tampilan utama dari aplikasi RapidMiner Studio 8.1.3 yang menyediakan beberapa menu untuk melakukan pengolahan data.

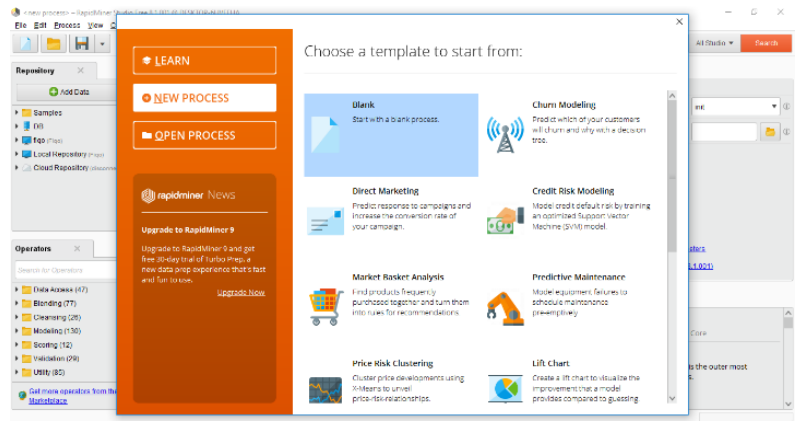

Gambar 2. Tampilan utama RapidMiner Studio 8.1.3

b) Memasukkan data yang akan diolah

Selanjutnya melakukan import data excel seperti yang terdapat pada Gambar 3.

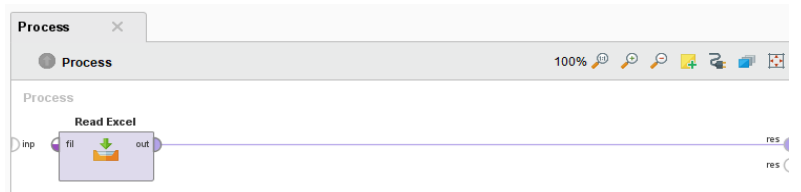

Gambar 3. Tampilan import data excel

c) Penyesuaian data

Penyesuaian data excel yang akan diolah dapat dilakukan dengan mengikuti perintah yang terdapat dalam Import Configuration Wizard. Tahap pertama yaitu diawali dengan memilih data excel akan diolah, sesuai pada Gambar 4. 


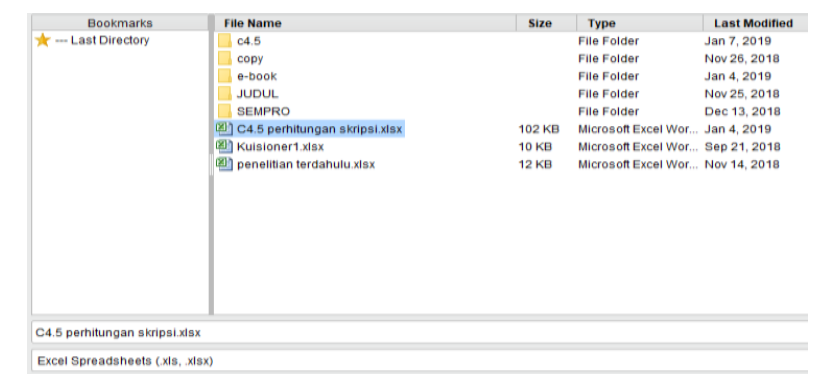

Gambar 4. Tampilan Tahap Pertama Import Configuration Wizard

d) Melakukan seleksi data yang akan diolah.

Kemudian akan tampil item data yang telah diseleksi (Gambar 5).

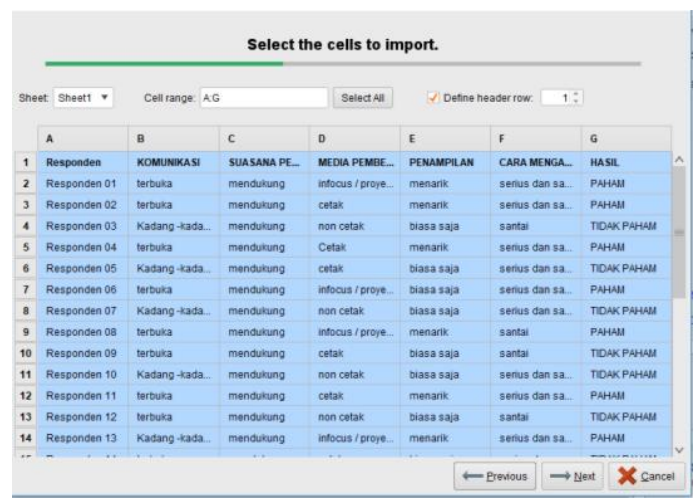

Gambar 5. Tampilan Tahap Kedua Import Configuration Wizard

e) Pemilihan model pengolahan data

Data yang sudah berhasil diimport kemudian diolah kedalam Decision tree dengan model pengolahan data sebagai berikut:

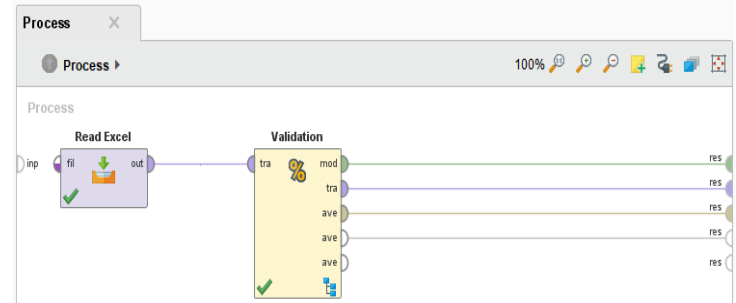

Gambar 6. Koneksivitas antara Data dan Model Pohon Keputusan (1)

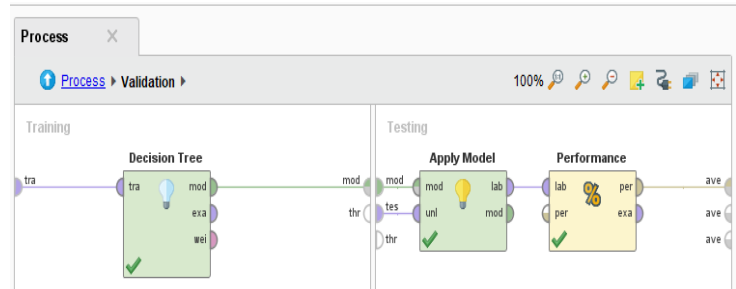

Gambar 7. Koneksivitas antara Data dan Model Pohon Keputusan (2) 
Setelah proses pengujian data dilakukan, telah didapat hasil akhir berupa pohon keputusan pada tingkat pemahaman mahasiswa terhadap matakuliah. Untuk Hasil pengolahan data dengan model pohon keputusan, dapat dilihat pada Gambar 8 sebagai berikut :

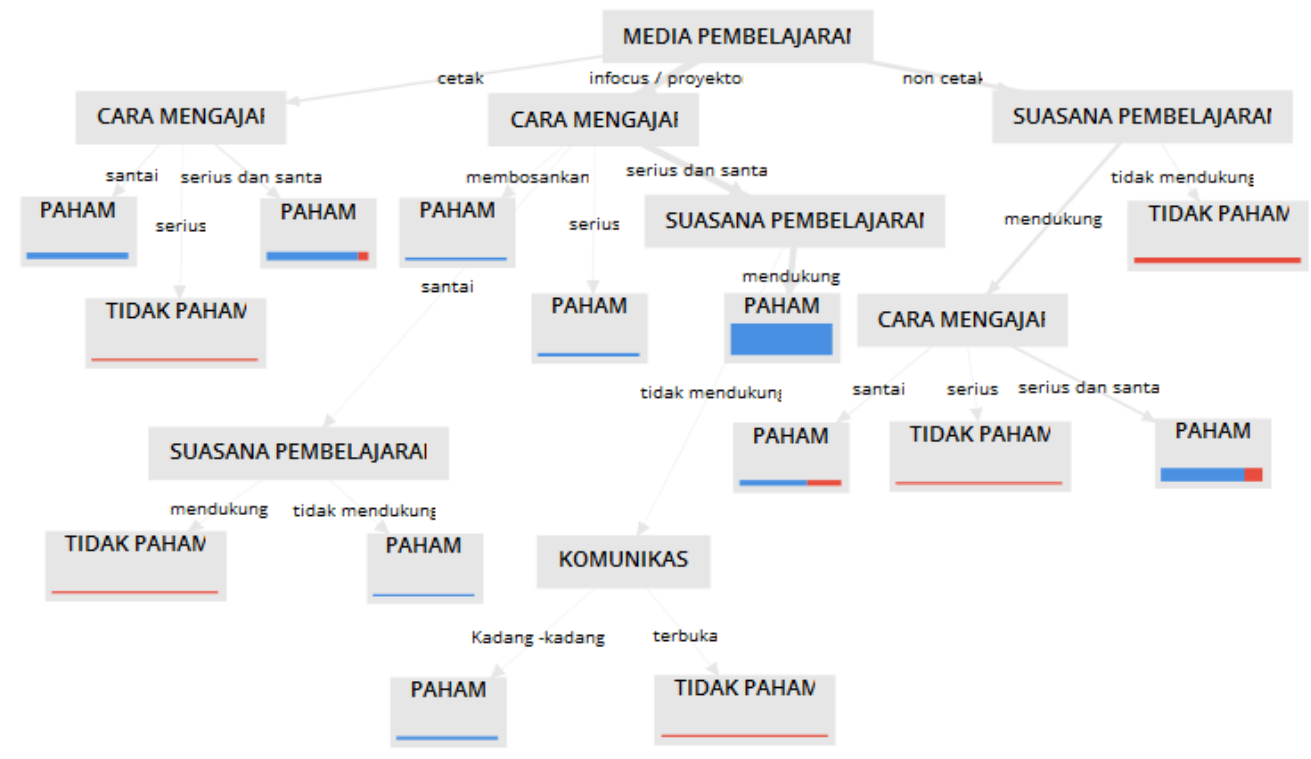

Gambar 9. Pohon keputusan klasifikasi tingkat pemahaman

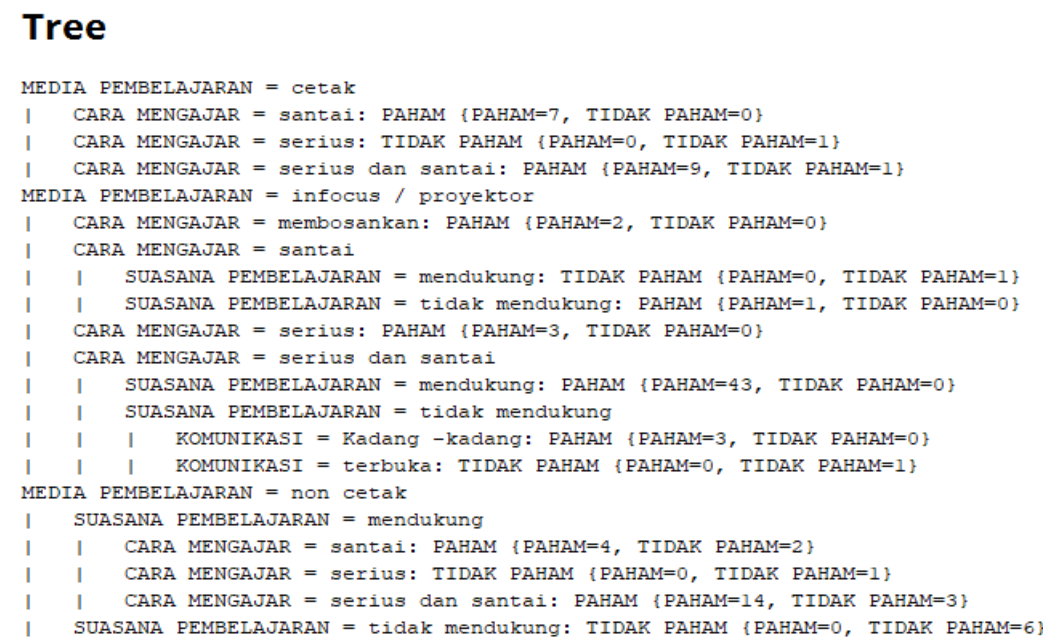

Gambar 10. Deskripsi pohon keputusan

Jika dilihat berdasarkan hasil pohon keputusan klasifikasi tingkat pemahaman mahasiswa yang terdapat pada Gambar 8, bahwa atribut yang mempunyai pengaruh utama untuk mendapatkan penyebab tingkat pemahaman adalah atribut C1 (Komunikasi) yang menempati sebagai simpul akar. Agar lebih jelas, peneliti membuat model aturan berupa teks, seperti pada Gambar 9 dengan penjelasan dalam tabel berikut: 
Tabel 3. Rules aturan C4.5 klasifikasi tingkat pemahaman mahasiswa.

\begin{tabular}{|c|c|c|}
\hline No & Rules & Keputusan \\
\hline 1 & $\begin{array}{l}\text { Jika Media Pembelajaran= Non Cetak dan Suasana } \\
\text { Pembelajaran= Tidak Mendukung }\end{array}$ & Tidak Paham \\
\hline 2 & $\begin{array}{l}\text { Jika Media Pembelajaran= Non Cetak dan Suasana } \\
\text { Pembelajaran= Mendukung dan Cara Mengajar= Santai }\end{array}$ & $\begin{array}{l}\text { PAHAM }(\text { Paham }=4 \\
\text { dan Tidak Paham }=2)\end{array}$ \\
\hline 3 & $\begin{array}{l}\text { Jika Media Pembelajaran= Non Cetak dan Suasana } \\
\text { Pembelajaran= Mendukung dan Cara Mengajar= Serius } \\
\text { dan Santai }\end{array}$ & $\begin{array}{l}\text { PAHAM (Paham }=14 \\
\text { dan Tidak Paham }=3)\end{array}$ \\
\hline 4 & $\begin{array}{l}\text { Jika Media Pembelajaran= Non Cetak dan Suasana } \\
\text { Pembelajaran= Mendukung dan Cara Mengajar= Serius }\end{array}$ & Tidak Paham \\
\hline 5 & $\begin{array}{l}\text { Jika Media Pembelajaran= Cetak dan Cara Mengajar= } \\
\text { Serius }\end{array}$ & Tidak Paham \\
\hline 6 & $\begin{array}{l}\text { Jika Media Pembelajaran= Cetak dan Cara Mengajar= } \\
\text { Serius dan Santai }\end{array}$ & $\begin{array}{l}\text { PAHAM }(\text { Paham }=9 \\
\text { dan Tidak Paham }=1)\end{array}$ \\
\hline 7 & $\begin{array}{l}\text { Jika Media Pembelajaran= Cetak dan Cara Mengajar= } \\
\text { Santai }\end{array}$ & Paham \\
\hline 8 & $\begin{array}{l}\text { Jika Media Pembelajaran= Infocus/Proyektor dan Cara } \\
\text { Mengajar= Serius }\end{array}$ & Paham \\
\hline 9 & $\begin{array}{l}\text { Jika Media Pembelajaran= Infocus/Proyektor dan Cara } \\
\text { Mengajar= Membosankan }\end{array}$ & Paham \\
\hline 10 & $\begin{array}{l}\text { Jika Media Pembelajaran= Infocus/Proyektor dan Cara } \\
\text { Mengajar= Santai dan Suasana Pembelajaran= Mendukung }\end{array}$ & Tidak Paham \\
\hline 11 & $\begin{array}{l}\text { Jika Media Pembelajaran= Infocus/Proyektor dan Cara } \\
\text { Mengajar= Santai dan Suasana Pembelajaran= Tidak } \\
\text { Mendukung }\end{array}$ & Paham \\
\hline 12 & $\begin{array}{l}\text { Jika Media Pembelajaran= Infocus/Proyektor dan Cara } \\
\text { Mengajar= Serius dan Santai dan Suasana Pembelajaran= } \\
\text { Mendukung }\end{array}$ & Paham \\
\hline 13 & $\begin{array}{l}\text { Jika Media Pembelajaran= Infocus/Proyektor dan Cara } \\
\text { Mengajar= Serius dan Santai dan Suasana Pembelajaran= } \\
\text { Tidak Mendukung dan Komunikasi= Terbuka }\end{array}$ & Tidak Paham \\
\hline 14 & $\begin{array}{l}\text { Jika Media Pembelajaran= Infocus/Proyektor dan Cara } \\
\text { Mengajar= Serius dan Santai dan Suasana Pembelajaran= } \\
\text { Tidak Mendukung dan Komunikasi= Kadang-kadang }\end{array}$ & Paham \\
\hline
\end{tabular}

Dapat dilihat dari hasil pohon keputusan dan model aturan berbentuk teks bahwa ada 14 rules yang dapat di jadikan sebagai referensi dalam menentukan tingkat pemahaman mahasiswa terhadap mata kuliah dengan 14 rules komplit sesuai pada tabel 4 seperti berikut:

1. Jika Media Pembelajaran $=$ Non Cetak dan Suasana Pembelajaran $=$ Tidak Mendukung, maka Hasil= Tidak Paham

2. Jika Media Pembelajaran $=$ Non Cetak dan Suasana Pembelajaran= Mendukung dan Cara Mengajar $=$ Santai, maka Hasil= PAHAM $($ Paham $=4$ dan Tidak Paham=2)

3. Jika Media Pembelajaran= Non Cetak dan Suasana Pembelajaran= Mendukung dan Cara Mengajar= Serius dan Santai, maka Hasil= PAHAM (Paham=14 dan Tidak Paham=3)

4. Jika Media Pembelajaran= Non Cetak dan Suasana Pembelajaran= Mendukung dan Cara Mengajar= Serius, maka Hasil= Tidak Paham 
5. Jika Media Pembelajaran= Cetak dan Cara Mengajar= Serius, maka Hasil $=$ Tidak Paham

6. Jika Media Pembelajaran= Cetak dan Cara Mengajar= Serius dan Santai, maka Hasil= 9 Paham dan 1 Tidak Paham

7. Jika Media Pembelajaran $=$ Cetak dan Cara Mengajar $=$ Santai, maka Hasil= Paham

8. Jika Media Pembelajaran= Infocus/Proyektor dan Cara Mengajar= Serius, maka Hasil= Paham

9. Jika Media Pembelajaran= Infocus/Proyektor dan Cara Mengajar= Membosankan, maka Hasil= Paham

10. Jika Media Pembelajaran= Infocus/Proyektor dan Cara Mengajar= Santai dan Suasana Pembelajaran= Mendukung, maka Hasil= Tidak Paham

11. Jika Media Pembelajaran= Infocus/Proyektor dan Cara Mengajar= Santai dan Suasana Pembelajaran= Tidak Mendukung, maka Hasil= Paham'

12. Jika Media Pembelajaran= Infocus/Proyektor dan Cara Mengajar= Serius dan Santai dan Suasana Pembelajaran= Mendukung, maka Hasil=Paham

13. Jika Media Pembelajaran= Infocus/Proyektor dan Cara Mengajar= Serius dan Santai dan Suasana Pembelajaran= Tidak Mendukung dan Komunikasi= Terbuka, maka Hasil= Tidak Paham

14. Jika Media Pembelajaran= Infocus/Proyektor dan Cara Mengajar= Serius dan Santai dan Suasana Pembelajaran= Tidak Mendukung dan Komunikasi= Kadang-kadang, maka Hasil= Paham.

Pada penelitian yang didukung hasil pemrosesan data menggunakan software RapidMiner didapat hasil akurasi penerapan algoritma C4.5 yaitu 87,10\%. Untuk melihat nilai akurasi dapat dilihat pada Gambar 11 dibawah ini:

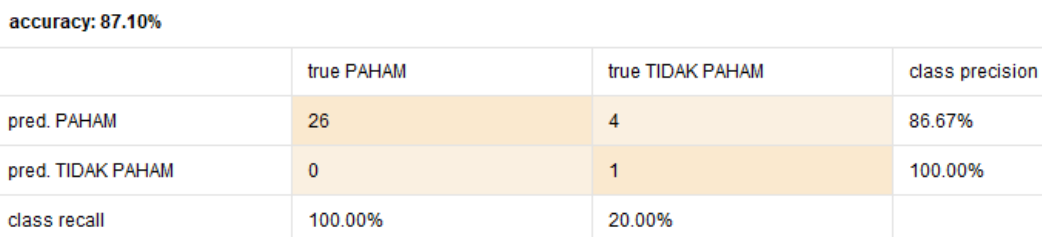

Gambar 11. Nilai Akurasi algoritma C4.5

\section{KESIMPULAN}

Hasil penelitian yang diperoleh disimpulkan bahwa telah di dapat klasifikasi tingkat pemahaman mahasiswa di STIKOM Tunas Bangsa yaitu empat belas (14) aturan atau rule keputusan dari target yang ingin dicapai yaitu Sembilan (9) keputusan Paham dan lima (5) keputusan Tidak Paham. Dan variabel yang memiliki prioritas utama terhadap tingkat pemahaman mahasiswa berdasarkan hasil perhitungan menggunakan algoritma C4.5 adalah dosen yang menggunakan media pembelajaran non cetak dan suasana pembelajaran yang mendukung dan cara mengajar yang santai serta serius dan santai. Pengaruh ini dapat dilihat dari bagaimana seorang dosen mampu membangun suasana kelas sehingga mahasiswa dapat memahami setiap materi ajaran. Dengan diperolehnya hasil yang sama antara perhitungan manual dengan pengujian menggunakan software RapidMiner, maka dapat disimpulkan bahwa penelitian ini telah berhasil. 


\section{DAFTAR PUSTAKA}

[1] M. Turnip, "Penerapan algoritma c4.5 untuk penentuan tingkat konsumsi konsumen pada medan solusindo," no. February, 2017.

[2] J. Han, M. Kamber, and J. Pei, Data Mining Concepts and Techniques. .

[3] M. Ridwan, H. Suyono, and M. Sarosa, "Penerapan Data Mining Untuk Evaluasi Kinerja Akademik Mahasiswa Menggunakan Algoritma Naive Bayes Classifier," Eeccis, vol. 7, no. 1, pp. 59-64, 2013.

[4] W. W. Ariestya, Y. E. Praptiningsih, and W. Supriatin, "Decision Tree Learning Untuk Penentuan Jalur Kelulusan Mahasiswa," Jurnal Ilmiah FIFO, vol. 8, no. 1, p. 97, 2016.

[5] D. T. Larose, Discovering Knowledge in Data: An Introduction to Data Mining. John Willey \& Sons, Inc, 2005.

[6] Y. sulistio Nugroho, "Penerapan Algoritma C4.5 untuk Klasifikasi Predikat Kelulusan Mahasiswa Fakultas Komunikasi dan Informatika Universitas Muhammadiyah Surakarta," Prosiding Seminar Nasional Aplikasi Sains \& Teknologi (SNAST), no. November, pp. 1-6, 2014.

[7] Pamungkas PDA, "Menentukan Kemungkinan Masuknya Calon Mahasiswa Baru Pada Sebuah Perguruan Tinggi Swasta Manggunakan Teknik Klasifikasi Pohon Keputusan Dengan Aplikasi Rapidminer 5.1," Jurnal Informatika, vol. 15, no. 1, pp. 45-55, 2015.

[8] F. F. Harryanto and S. Hansun, "Penerapan Algoritma C4 . 5 untuk Memprediksi Penerimaan Calon Pegawai Baru di PT WISE," no. March, 2017.

[9] E. Elisa, "Analisa dan Penerapan Algoritma C4.5 Dalam Data Mining Untuk Mengidentifikasi Faktor-Faktor Penyebab Kecelakaan Kerja Kontruksi PT.Arupadhatu Adisesanti,” Jurnal Online Informatika, vol. 2, no. 1, p. 36, 2017.

[10] F. F. Harryanto, S. Hansun, U. M. Nusantara, G. Serpong, and C. Pegawai, "Penerapan Algoritma C4 . 5 untuk Memprediksi Penerimaan Calon Pegawai Baru di PT WISE,” vol. 3, no. 2, pp. 95-103, 2017.

[11] R. H. Pambudi, B. D. Setiawan, and Indriati, "Penerapan Algoritma C4 . 5 Untuk Memprediksi Nilai Kelulusan Siswa Sekolah Menengah Berdasarkan Faktor Eksternal," Jurnal Pengembangan Teknologi Informasi dan Ilmu Komputer, vol. 2, no. 7, pp. 2637-2643, 2018.

[12] D. M. Agustina and Wijanarto, "Analisis Perbandingan Algoritma ID3 Dan C4 . 5 Untuk Klasifikasi Penerima Hibah Pemasangan Air Minum," Journal of Applied Intelligent System, vol. 1, no. 3, pp. 234-244, 2016.

[13] L. Swastina, "Penerapan Algoritma C4 . 5 Untuk Penentuan Jurusan Mahasiswa," vol. 2, no. 1, 2013.

[14] V. S. Moertini, B. Sitohang, and O. S. Santosa, "Integrasi Algoritma Pohon Keputusan C4.5 Yang Dikembangkan Ke Dalam Object-Relational Dbms," JUTI: Jurnal Ilmiah Teknologi Informasi, vol. 6, no. 2, p. 39, 2007.

[15] B. Setiadi, "Penerapan algoritma decision tree c4.5 untuk penilaian rumah tinggal," vol. 16, no. 2, pp. 195-206, 2015.

[16] A. P. Windarto, "Penerapan algoritma c4.5 untuk klasifikasi predikat keberhasilan mahasiswa di amik tunas bangsa," no. July, 2016.

[17] R. Wajhillah and I. Yulianti, "Penerapan algoritma c4.5 untuk prediksi penggunaan jenis kontrasepsi berbasis web," Kumpulan jurnaL Ilmu Komputer (KLIK), vol. 4, no. 2, pp. 174$187,2017$.

[18] Oktafianto, "ANALISIS KEPUASAN MAHASISWA TERHADAP PELAYANAN AKADEMIK MENGGUNAKAN METODE ALGORITMA C4 . 5," vol. 2, no. 1, pp. 1-11, 2016.

[19] I. Parlina, A. P. Windarto, A. Wanto, and M. R. Lubis, "Memanfaatkan Algoritma K-Means dalam Menentukan Pegawai yang Layak Mengikuti Asessment Center untuk Clustering Program SDP," CESS (Journal of Computer Engineering System and Science), vol. 3, no. 1, pp. 87-93, 2018.

[20] M. G. Sadewo, A. P. Windarto, and A. Wanto, "Penerapan Algoritma Clustering dalam Mengelompokkan Banyaknya Desa/Kelurahan Menurut Upaya Antisipasi/ Mitigasi Bencana Alam Menurut Provinsi dengan K-Means," KOMIK (Konferensi Nasional Teknologi Informasi dan Komputer), vol. 2, no. 1, pp. 311-319, 2018.

[21] R. W. Sari, A. Wanto, and A. P. Windarto, "Implementasi Rapidminer dengan Metode K-Means 
(Study Kasus: Imunisasi Campak pada Balita Berdasarkan Provinsi)," KOMIK (Konferensi Nasional Teknologi Informasi dan Komputer), vol. 2, no. 1, pp. 224-230, 2018.

[22] A. P. Windarto, "Implementation of Data Mining on Rice Imports by Major Country of Origin Using Algorithm Using K-Means Clustering Method," International Journal of artificial intelligence research, vol. 1, no. 2, pp. 26-33, 2017.

[23] A. P. Windarto, P. Studi, S. Informasi, and D. Mining, "Penerapan Data Mining Pada Ekspor Buah-Buahan Menurut Negara Tujuan Menggunakan K-Means Clustering,” vol. 16, no. 4, pp. 348-357, 2017.

[24] S. Sudirman, A. P. Windarto, and A. Wanto, "Data Mining Tools | RapidMiner: K-Means Method on Clustering of Rice Crops by Province as Efforts to Stabilize Food Crops In Indonesia," IOP Conference Series: Materials Science and Engineering, vol. 420, no. 12089, pp. $1-8,2018$.

[25] "PENERAPAN DATA MINING DALAM MENGANALISIS KEPRIBADIAN PENGGUNA MEDIA SOSIAL DENGAN NAÏVE BAYES CLASSIFIER : STUDI KASUS,” vol. 1, no. 1, p. 5258, 2016.

[26] D. Ispriyanti and A. Hoyyi, "Analisis klasifikasi masa studi mahasiswa prodi statistika undip dengan metode support vector machine (svm) dan id3 (iterative dichotomiser 3) 1,2," vol. 9, no. 1 , pp. $15-29,2016$.

[27] Nurjoko and H. Kurniawan, "Aplikasi Data Mining Untuk Memprediksi Tingkat Kelulusan Mahasiswa Menggunakan Algoritma Apriori di IBI Darmajaya, Bandar Lampung," Jurnal TIM Darmajaya, vol. 2, no. 1, pp. 79-93, 2016.

[28] A. Yuliana and D. B. Pratomo, "Memprediksi Kepuasan Mahasiswa Terhadap Kinerja Dosen Politeknik TEDC Bandung," Semnasinotek 2017, pp. 377-384, 2017. 